Jansen and Roche., Speakers bureau: Consultation fees/participation in company sponsored speaker's bureau from Pfizer, Lilly, Sobi, Celgene, Novartis, Roche and Sanofi., Ricardo Blanco Grant/research support from: Abbvie, MSD, and Roche, Consultant for: Abbvie, Pfizer, Roche, BristolMyers, Janssen, Speakers bureau: Abbvie, Pfizer, Roche, Bristol-Myers, Janssen

DOI: 10.1136/annrheumdis-2019-eular.3623

\section{THU0314 OUTCOMES OF PATIENTS TREATED WITH TOCILIZUMAB OR ABATACEPT AS STEROID-SPARING AGENTS WITH GIANT CELL ARTERITIS}

Daniela Rossi, Irene Cecchi, Elena Rubini, Massimo Radin, Savino Sciascia, Dario Roccatello. University of Turin, Turin, Italy

Background: Giant cell arteritis (GCA) is a common form of systemic vasculitis. The current mainstay of GCA management is glucocorticoid (GC) therapy. Recently, at least 2 biological therapies [tocilizumab (TCZ)

Abstract THU0314 -Table 1.

Table 1. Characteristics of the patients included in the study

\begin{tabular}{|c|c|c|}
\hline & $\begin{array}{l}\text { Total number of } \\
\text { patients (33) }\end{array}$ & $\%$ \\
\hline \multicolumn{3}{|l|}{ Demographic characteristics } \\
\hline Female/Male & $21 / 12$ & \\
\hline Age (years) (mean, SD) & $73.6 \pm 8.7$ & \\
\hline \multicolumn{3}{|l|}{ Clinical characteristics at the onset of GCA } \\
\hline Fever $(n)$ & 12 & 36.4 \\
\hline Fatigue (n) & 18 & 54.5 \\
\hline Headache (n) & 28 & 84.8 \\
\hline Scalp tenderness $(n)$ & 8 & 24.2 \\
\hline Jaw claudication $(n)$ & 15 & 45.4 \\
\hline Vision loss (n) & 16 & 48.5 \\
\hline PMR (n) & 11 & 33.3 \\
\hline \multicolumn{3}{|l|}{ Diagnosis } \\
\hline Biopsy proven & $27 / 32$ & 84.4 \\
\hline PET positivity & $12 / 29$ & 41.4 \\
\hline Eco-color-doppler positivity & $30 / 31$ & 97 \\
\hline \multicolumn{3}{|l|}{ GC therapy } \\
\hline Previous methylprednisolone pulses (n) & 7 & 21.2 \\
\hline Oralprednisone (n) & 33 & 100 \\
\hline Dose of oral prednisone (mg/day) (mean, SD) & $49.7 \pm 15.1$ & \\
\hline \multicolumn{3}{|l|}{ Previous immunosuppressive therapies } \\
\hline Methotrexate (n) & 11 & 33.3 \\
\hline Mean dose (mg/week) (mean, SD) & $15.6 \pm 1.7$ & \\
\hline Mycophenolate $(n)$ & 6 & 18.1 \\
\hline Mean dose ( $\mathrm{g} /$ day) (mean, $\mathrm{SD})$ & $2.2 \pm 0.4$ & \\
\hline
\end{tabular}

and abatacept $(A B A)$ ] have been proven to be effective in the management of CGA in randomized controlled trials. Nevertheless, their use as steroid sparing agents might need further investigation.

Objectives: We aimed to investigate the steroid-sparing effect of biological therapies, namely TCZ and ABA, in a cohort of GCA patients when compared to standard GC treatment.

Methods: We retrospectively collected data from GCA patients who attended the S.G. Bosco Hospital, Turin, Italy, who were treated with TCZ, both intravenous (IV) and subcutaneous (SC), and/or ABA SC (8 $\mathrm{mg} / \mathrm{kg} / \mathrm{month}, 162 \mathrm{mg} /$ week, and $125 \mathrm{mg} /$ week respectively). These therapies were prescribed as first line agents or as second line when patients were refractory/intolerant/contraindicated to standard immunosuppressive therapies. Complete response to the treatment was define as a clinical and serological remission after 12 months of therapy; partial response was defined as clinical or serological remission after 12 months of therapy.

Results: This retrospective study included 33 GCA patients [mean age 74 (range $85-57$ ), females $63 \%$, mean follow-up from GCA diagnosis 44.4 \pm 33.5 months). Table 1 resumes the characteristics of the GCA patients included in the study.

Twenty-eight patients out of $33(85 \%)$ received one biologic agent. Five patients (15\%) needed a therapeutic switch (one patient from TCZ to $\mathrm{ABA}$, and 4 patients from $\mathrm{ABA}$ to $\mathrm{TCZ})$. Patients were treated as follow: 9 with TCZ IV, 11 with TCZ SC, and 18 with ABA. Among the TCZ IV group, all patients experienced a response (57\% complete response, and $43 \%$ partial response). Among the TCZ SC group, $83 \%$ experienced a response $(67 \%$ complete response, and $16 \%$ partial response). Among the ABA group, $86 \%$ experienced a response (36\% complete response and $50 \%$ partial response). After 12 months of therapy, $100 \%$ of patients in TCZ groups, both IV and SC, and $64.2 \%$ of ABA group were treated with low doses of oral prednisone ( $\leq 7.5 \mathrm{mg} /$ day) as maintenance. We noticed a significant reduction of inflammatory parameters [C-reactive protein (CRP) and erythrocyte sedimentation rate (ESR)] after 12 months of therapy with TCZ [TCZ IV group: mean baseline CRP (mg/dl) 1.9 \pm 2.3 , mean CRP after 12 months of therapy $0,3 \pm 0.2$; mean baseline ESR $(\mathrm{mm} / \mathrm{h})$ 58.1 \pm 25.6 , mean ESR after 12 months $9.5 \pm 4.2$; TCZ SC group: mean baseline CRP 4.5 \pm 3.8 , mean CRP after 12 months $0.2 \pm 0.2$; mean baseline ESR 51.9 \pm 27 , mean ESR after 12 months $6.5 \pm 6]$. When compared to standard GC regimen [1], in patients treated with TCZ, both IV and SC, we estimated a median steroid-sparing effect quantifiable in 30 $\mathrm{mg} /$ daily in the first month and an overall steroid-sparing effect of $15 \mathrm{mg} /$ daily when assessed in 12 months.

Conclusion: This retrospective study confirms the efficacy of biologica therapies in the management of CGA. Besides, in our experience TCZ allowed a significant reduction of GCs use, especially in the first month of therapy, when compared to standard GCs based regimens.

\section{REFERENCE:}

[1] Dasgupta B, et al. BSR and BHPR Standards, Guidelines and Audit Working Group. BSR and BHPR guidelines for the management of giant cell arteritis. Rheumatology. 2010 Aug;49(8):1594-7.

Disclosure of Interests: None declared

DOI: 10.1136/annrheumdis-2019-eular.4807

\section{THU0315 SEVERITY AND RESPONSE TO INDUCTION THERAPY IN NEW AND RELAPSING ANCA ASSOCIATED VASCULITIS PATIENTS - REAL WORLD PRACTICE DATA}

Peter Rutherford, Dieter Götte. Vifor Pharma, Medical, Zurich, Switzerland

Background: ANCA-associated vasculitis (AAV) presents clinically with variable severity of disease and current clinical guidelines give varying advice on initial treatment to induce remission. Achieving remission quickly is important to gain disease control and avoid cumulative organ damage from treatment related adverse events.

Objectives: This study examined real world practice of AAV treatment in Europe to understand the AAV severity spectrum and the response to therapy over 12 months.

Methods: 929 incident and 268 relapsing EU AAV patients receiving care from 399 physicians were studied. Patients were referred between 201417 and data collected retrospectively at baseline and 1, 3, 6 and 12 months following induction therapy. Birmingham Vasculitis Activity Score (BVAS) was collected in only $12 \%$ of patients and severity was defined as mild (localized disease with no systemic symptoms), moderate (Mod, systemic disease with lung and/or kidney involvement) or systemic (rap idly progressive systemic disease with lung and/or kidney involvement). Results: AAV disease severity varied in both incident (mild $12.2 \%$, moderate $54.3 \%$, severe $33.6 \%$ ) and relapsing (corresponding values 9.7, 64.6 and 25.7) patients at start of treatment. Comorbidity at time of

Abstract THU0315 -Table 1

\begin{tabular}{|c|c|c|c|c|c|c|c|c|c|c|c|c|}
\hline & \multicolumn{3}{|c|}{1 month } & \multicolumn{3}{|c|}{3 months } & \multicolumn{3}{|c|}{6 months } & \multicolumn{3}{|c|}{12 months } \\
\hline & Mild & Mod & Severe & Mild & Mod & Severe & Mild & Mod & Severe & Mild & Mod & Severe \\
\hline Full & 55.3 & 21.0 & 13.5 & 59.4 & 47.2 & 28.7 & 82.6 & 64.7 & 45.0 & 82.8 & 70.7 & 53.5 \\
\hline Partial & 42.2 & 74.1 & 67.9 & 38.4 & 48.8 & 56.8 & 14.5 & 32.0 & 40.6 & 17.2 & 26.0 & 35.7 \\
\hline No & 2.5 & 4.9 & 18.6 & 2.2 & 4.0 & 14.5 & 2.9 & 3.3 & 14.4 & 0 & 3.3 & 10.8 \\
\hline
\end{tabular}

